Available online at $\underline{\mathrm{http}} \mathrm{://jddtonline.info}$ REVIEW ARTICLE

\title{
TRYPSIN, RUTOSIDE AND BROMELAIN ALONE AND FIXED DOSE COMBINATION: A NATURAL, SAFER AND EFFECTIVE ANTI-INFLAMMATORY AGENT
}

\author{
*DR. Rimplejeet Kaur
}

Senior Resident, Department of Pharmacology, All India Institute of Medicine, Jodhpur

DR. Sneha Abmwani

Professor and Head, Department of Pharmacology, All India Institute of Medicine, Jodhpur

\author{
Dr. Bharati Mehta
}

Associate Professor, Department of Pharmacology, All India Institute of Medicine, Jodhpur

*Corresponding Author's Email: sidhurimple@yahoo.com

\begin{abstract}
:
Millions of patients worldwide with chronic musculoskeletal symptoms are on long term therapy with non-steroidal antiinflammatory drugs (NSAIDs). But the unfortunate fact is that these drugs have common and potentially severe adverse effects, including renal impairment, gastrointestinal complications and cardiotoxicity. The cardiotoxic effect produced by these drugs is particularly worrying because many patients have both cardiovascular disease and musculoskeletal disease. Clinicians and medical researchers worldwide are in general agreement that pharmacologic pain treatment for musculoskeletal conditions is unsatisfactory and the irrationale use of NSAIDs in such conditions is adding the agony of the patients. Thus new drugs are needed to replace NSAIDs to treat musculoskeletal diseases. Newer natural and safer alternatives identified in recent past are Bromelain, Trypsin and Rutoside. Their combination to treat inflammatory diseases is a coming out with promising results.
\end{abstract}

Key-Words: Trypsin, Rutoside, Bromelain, Anti-Inflammatory

\section{INTRODUCTION:}

The most common reason for people seeking the advice of health professionals is that they are in some sort of pain. In general, pain is symptom of some form of dysfunction and resultant inflammatory processes in the body ${ }^{1}$.

Many drugs are available that help to reduce inflammation and relieve pain. They act by interfering with the body's natural inflammatory response mechanisms; however their chronic use may lead to side effects.

Over the past few years research suggest role for more natural and safe alternatives for the management of pain and inflammation. Some areas of research include supplemental essential fatty acids, herbs such as ginger, turmeric, and boswellia, proteases (trypsin, bromelain) and bioflavonoids (rutoside).

Recent clinical studies show that the Bromelain, Trypsin and Rutoside fixed dose combination to be a very potent and safe in relieving oedema, inflammation and promoting wound healing.

The anti-inflammatory effect of proteolytic enzymes has been proved by several clinical studies and is considered to a promising treatment for acute (e.g., sports) injuries, post-surgery and degenerative joint conditions ${ }^{2-7}$. Common proteases include bromelain from pineapple; trypsin, chymotrypsin from porcine (pig) or bovine (cow) origin. However, porcine sources yield higher specific activity than do bovine sources ${ }^{1}$.
The individual therapeutic role of these natural substances was established long back in 1960s but in recent years further clinical studies were done to prove this role more substantially and now there is sufficient evidence that the combination of Bromelain, Trypsin and Rutoside has a significant implication in alleviate oedema and inflammation.

In this article the anti-inflammatory activity of Bromelain, Trypsin and Rutoside as individual drugs and their fixed dose combination has been discussed.

\section{TRYPSIN:}

Trypsin is produced in the pancreas in the form of the inactive zymogen trypsinogen. When the pancreas is stimulated by cholecystokinin, it is then secreted into the duodenum via the pancreatic $\operatorname{duct}^{8}$. Once in the duodenum, the enzyme enteropeptidase activates it into trypsin by proteolytic cleavage. Trypsin in the duodenum catalyses the hydrolysis of peptide bonds so that proteins can be broken down into smaller peptides ${ }^{9}$.

Clinical studies exhibit that the anti-inflammatory effect of trypsin is possibly due to inhibitory action on the vascular permeability ${ }^{10}$ and its ability to inhibit the rise in C-reactive protein and enhance the rise in alpha 1antitrypsin, alpha 2-macroglobulin ${ }^{11}$. Trypsinchymotrypsin has also been shown to modulate cytokine levels in burns ${ }^{4}$.

\section{BROMELAIN}

Bromelain is a crude extract from the pineapple that contains, among other components, various closely 
related proteinases, demonstrating, in vitro and in vivo, antiedematous, antiinflammatory, antithrombotic and fibrinolytic activities ${ }^{12}$.

Bromelain when applied topically as a cream $(35 \%$ bromelain in a lipid base) is beneficial in the elimination of burn debris and in acceleration of healing ${ }^{13}$. Several groups have provided significant evidence for both the edema-protective and edema-reducing efficacy of bromelain in various animal experiments ${ }^{14}$.

Bromelain is used as an anti-inflammatory and analgesic agent in treating the symptoms of arthritis ${ }^{31-33}$. The analgesic and anti-inflammatory effects are reportedly due to inhibition of the arachidonic acid pathway of inflammation by selectively decreasing thromboxane generation, changing the ratio of thromboxane/prostacyclin (in favor of prostacyclin), and inhibiting PGE2 in addition to the direct effects on the nociceptors 15,16 . Other reported anti-inflammatory mechanisms of action of bromelain include inhibition of bradykinin at the site of inflammation via depletion of the plasma kallikrein system, and limiting the formation of fibrin by reduction of clotting cascade intermediates ${ }^{17,18}$. A few clinical trials in patients with arthritis reported statistical equivalence of pain reduction, whether they were treated with bromelain or diclofenac ${ }^{19}$.

\section{RUTOSIDE}

Rutoside is a natural flavone derivative. It has antiinflammatory, anti-allergy and immunomodulating activity ${ }^{20}$. Rutoside inhibits platelet aggregation, as well as decreasing capillary permeability, making the blood thinner and improving circulation. Rutin also strengthens the capillaries. It helps to prevent venous edema of the legs. Thus, rutoside is useful in the management of venous edema and capillary fragility ${ }^{21}$.

Rutoside is a powerful anti-oxidants and effectively combat the harmful free radicals such as nitric oxide, released during the inflammatory process ${ }^{22,23}$.

Rutoside also suppresses the major inflammatory and proarthritic mediators of macrophages ${ }^{24}$. The ability of Rutoside to decrease MCP-1 levels in vivo and in vitro may add to its beneficial effects because this cytokine is a potent stimulator of monocyte recruitment into the site of inflammation ${ }^{25}$. Rutoside also inhibit the phosphorylation and activation of Jun N-terminal kinase/stress-activated protein kinase, leading to the suppression of AP-1 activation. They also decrease the activation of NF- $\mathrm{NB}$ in both human and experimental models 26,27 .

\section{COMBINATION OF TRYPSIN, RUTOSIDE AND BROMELAIN}

Combination of Trypsin, Rutoside and Bromelain has shown to have significant anti-inflammatory effects in several clinical studies. However, the combined mechanism of action of these agents is not clear and need to be explored further.
In a clinical study conducted in 2004, the efficacy of an enzyme-flavonoid mixture was compared with diclofenac, a prescription $\mathrm{NSAID}^{28}$. The proteolytic enzymes used were bromelain and trypsin. These three agents were used in the form of an enteric-coated tablet (to prevent the enzymes from being destroyed by stomach acid) that contained $90 \mathrm{mg}$ of bromelain, $48 \mathrm{mg}$ of trypsin, and $100 \mathrm{mg}$ of rutoside.

For the 6-week trial, the researchers recruited 103 middle-aged patients who had painful osteoarthritis of the knee with a disease flare in one knee joint. The results showed that diclofenac and the bromelain/trypsin/rutoside mixture were about equally effective in relieving the patients' pain and improving their mobility, with no serious adverse events in either case $^{28}$

In another clinical study conducted in 2006, the Phlogenzym- (PE-fixed dose combination of trypsin, bromelain and rutoside) was compared to the nonsteroidal anti-inflammatory drug (NSAID) diclofenac in patients with osteoarthritis of the hip. After six weeks of observation this trial showed significant non-inferiority from 6 weeks treatment with $\mathrm{PE}$ in patients with osteoarthritis of the hip and with regard to drug tolerability some tendencies in favour of PE. Thus, PE may well be recommended for the treatment of patients with osteoarthritis of the hip with signs of inflammation as indicated by a high pain level.

\section{CONCLUSION}

Over the past many decades anti inflammatory drugs NSAIDs are being used very extensively all over the world but their chronic use may lead to side effects such as gastric ulcers and liver- kidney damage. After bitter experiences with NSAIDs like Rofecoxib and Valdecoxib, virtually all NSAIDs come with a warning about potential increased risks of heart attack and stroke with their use. A recent study on the cardiovascular safety of NSAIDs has highlighted further evidence that diclofenac is associated with cardiovascular risks that are higher than the other non-selective NSAIDs, and similar to the selective COX-2 inhibitors ${ }^{30}$.Thus their frequent use is not recommended. Another group of drugs used in severe inflammatory conditions are steroids that contribute to even more severe and serious adverse effects on long-term use.

Considering these facts, the use of drugs of natural origin with lesser hazards is a positive alternative. Bromelain, Rutoside and Trypsin are known to have a very promising role in relieving inflammation and promote wound healing and based on the clinical studies performed on their combination, the Bromelain, Rutoside and Trypsin combination might be a safer alternative in comparison to other drugs used for these conditions. Although further studies need to be done to determine how each individual drug affects the activity of another two ingredients in this combination. 


\section{REFERENCES}

1. Mark Percival. Understanding The Natural Management of Pain and Inflammation Clinical Nutrition Insights. Advanced Nutrition Publications, Inc., rev. 1999

2. Bucci LR. Nutrition Applied to Injury Rehabilitation and Sports Medicine. Boca Raton: CRC Press, 1995.

3. Izaka K, et al. Gastrointestinal absorption and anti-inflammatory effect of bromelain. Japan J Pharmacol 1972;22:519-34.

4. Taussig SJ, Batkin S. Bromelain, the enzyme complex of pineapple (Ananas comosus) and its clinical application. An update. J Ethnopharmacology 1988;22:191-203.

5. Christie RB. The medical uses of proteolytic enzymes. In: Wisman A. (ed.) Topics in enzyme and fermentation biotechnology. Chicester, England: Ellis Horwood Ltd 1980; 25-83.

6. Blonstein JL. Oral enzyme tablets in the treatment of boxing injuries. The Practitioner 1967; 198:547-8.

7. Shaw PC. The use of a trypsin-chymotrypsin formulation in fractures of the hand. Br J Clin Practice 1969;23(1):25.

8. Beck TW, Housh TJ, Johnson GO, et al. Effects of a protease supplement on eccentric exercise-induced markers of delayedonset muscle soreness and muscle damage. J Strength Cond Res. 2007;21:661-667.

9. Rawlings ND, Barrett AJ . "Families of serine peptidases". Methods in Enzymology. 1994; 244: 19-61.

10. Zatuchni GI, Colombi DJ. Bromelains therapy for the prevention of episiotomy pain. Obstet Gynecol. 1967;29:275278 .

11. The German physiologist Wilhelm Khne (1837-1900) discovered trypsin in 1876. See: W. Khne (1877) "ber das Trypsin (Enzym des Pankreas)", Verhandlungen des naturhistorisch-medicinischen Vereins $\mathrm{zu}$ Heidelberg, new series, vol. 1, no. 3, pages 194-198.

12. Latha B, Ramakrishnan KM, Jayaraman V, Babu M. Action of trypsin: chymotrypsin (Chymoral forte DS) preparation on acute-phase proteins following burn injury in humans. Burns. 1997 Mar Suppl 1:S3-7.

13. Bromelain: biochemistry, pharmacology and medical use. Cell Mol Life Sci. 2001 Aug;58(9):1234-45.

14. Neubauer R. A. ( 1961) A plant protease for potentiation of and possible replacement of antibiotics. Exp. Med. Surg. 19: $143-$ 160.

15. Taussig SJ, et al. Bromelain, the enzyme complex of pineapple (Ananas comosus) and its clinical application. An update. $J$ Ethnopharmacol. 1988;27:191-203.

16. Felton GE. Fibrinolytic and antithrombotic action of bromelain may eliminate thrombosis in heart patients. Med Hypotheses. Nov1980;6(11):1123-33.

17. Kumakura S, Tsurufuji S, Yamashita M. Effect of bromelain on kaolin-induced inflammation in rats. Eur $J$ Pharmacol. 1988;150:295-301.

18. Uchida Y, Katori M. Independent consumption of high and low molecular weight kininogens in vivo. Adv Exp Med Biol. 1986;198:113-118.

19. Klein G, et al. Reducing pain by oral enzyme therapy in rheumatic diseases. Wien Med Wochenschr. 1999;149(2122):577-80

20. Comparative study of flavonoids in experimental models of inflammation Alejandra Ester Rotelli' , Teresita Guardia, Américo Osvaldo Juárez, Nadir Ernesto de la Rocha, Lilian Eugenia Pelzer. Pharmacological Research.Vol 48, iss 6, 2003; 601-606.

21. Taussig SJ, Batkin S. Bromelain, the enzyme complex of pineapple (Ananus comosus) and its clinical application: An update. J. Ethnopharmacol 1988; 22: 191 - 203.

22. Taussig SJ. The mechanism of the physiological action of bromelain. Medical hypotheses. 1980; 6(1): 99-104.

23. Shahid SK, Turakhia NH, Kundra M, Shanbag P, Daftary GV, Schiess W. Efficacy and safety of Phlogenzym-A protease formulation, in sepsis in children. JAPI. 2002; 50: 527-531.

24. La Cassa C, Villegas I, Alacron de la Lastra C, Motilva V, Martin Calero MJ. Evidence for protective and antioxidant properties of rutin, a natural flavone, against ethanol induced gastric lesions. J Ethnopharmacol. 2000; 71: 45-53.

25. Rutoside decreases human macrophage-derived inflammatory mediators and improves clinical signs in adjuvant-induced arthritisTina Kauss 1 , Daniel Moynet, Jérôme Rambert, Abir Al-Kharrat, Stephane Brajot, Denis Thiolat, Rachid Ennemany, Fawaz Fawaz_and M Djavad Mossalayi_Arthritis Research \& Therapy 2008, 10 .

26. Rot A, von Andrian UH: Chemokines in innate and adaptive host defense: basic chemokinese grammar for immune cells. Annu Rev Immunol 2004, 22:891-928.

27. Rovenska E, Svik K, Stancikova M, Rovensky J. Inhibitory effect of enzyme therapy and combination therapy with cyclosporin A on collagen-induced arthritis. Clin Exp Rheumatol. May2001;19(3):303-9.

28. Akhtar NM, Naseer R, Farooqi AZ, et al. Oral enzyme combination versus diclofenac in the treatment of osteoarthritis of the knee-a double-blind prospective randomized study. Clin Rheumatol 2004;23:410-5.

29. Non-steroidal anti-inflammatory drugs (NSAIDs): further evidence that the cardiovascular risk with diclofenac is higher than other non-selective NSAIDs and similar to the selective COX-2 inhibitors. Drug Safety Update October 2012, vol 6, issue 3: S1. 